\title{
Crítica e justificação em Rainer Forst*
}

\author{
Rúrion Melo \\ Professor de Ciência Política na USP e pesquisador do Cebrap
}

Resumo: 0 presente texto procura analisar as características principais do projeto em desenvolvimento de uma teoria crítica da política elaborado por Rainer Forst. Após identificar rapidamente a posição de Forst no quadro da teoria crítica, apresentarei a ideia dos "contextos de justificação". Em seguida, com base em seus escritos mais recentes, pretendo mostrar de que maneira uma teoria crítica da sociedade baseada na "crítica das relações de justificação" está vinculada propriamente a questões da filosofia política normativa. Por fim, com 0 intuito de avaliar sua teoria de maneira crítica, levantarei alguns problemas que dizem respeito ao método "construtivista" assumido pelo autor e apontarei algumas dificuldades em se fundamentar uma crítica da sociedade em uma teoria construtivista que, ao que parece, está fundada no primado "moral".

Palavras-chave: crítica; justificação; Rainer Forst; teoria crítica; teoria política normativa.
Ahstract: This paper analyzes the main features of the on going project of a critical theory of politics elaborated by Rainer Forst. After identifying Forst's position in the context of the critical theory, I introduce his idea of "contexts of justification". Then, based on his more recent writings, I intend to show how a critical theory of society based on "critical relations of justification" is strictly linked to questions of normative political philosophy. Finally, in order to evaluate his theory in a critical way, I raise some issues related to the "constructivist" method assumed by the author and point out some difficulties of grounding a critique of society in a constructivist theory which, it seems, is grounded in a "moral" primacy.

Keywords: critique; justification; Rainer Forst; critical theory; normative political theory.

Texto apresentado em 2012 no GT Teorias da Justiça do XV Encontro Nacional Anpof. Agradeço a todos os participantes do GT pelas críticas e sugestões, em especial à profa Marina Velasco. 
Teoria crítica e filosofia política permaneceram estranhamente dissociadas por décadas. Os papéis ocupados por determinadas disciplinas na composição interdisciplinar da teoria crítica a partir de 1930 (a economia política, a psicanálise e a teoria da cultura) confluíram para uma filosofia social que tendeu a considerar a política subordinada à base socioeconômica, permitindo assim "pouco impulso para a elaboração de uma teoria autônoma da política"1. Apesar da importância de Franz Neumann² para a primeira geração de autores vinculados à teoria crítica, não seria forçoso dizer que apenas com Jürgen Habermas abriu-se de forma mais explícita uma nova perspectiva para a teoria crítica em solidariedade com reflexões da moral e da política, do direito e da democracia ${ }^{3}$. À luz desse processo, os trabalhos de Rainer Forst, representante da "quarta geração", parecem radicalizar uma articulação entre teoria social e filosofia política normativa ao lidar com questões do pensamento político contemporâneo. O presente texto procura analisar as características principais do projeto em desenvolvimento de uma teoria crítica da política elaborado por Rainer Forst. Após identificar rapidamente a posição de Forst no quadro da teoria crítica (I), apresentarei a ideia dos "contextos de justificação" (II). Em seguida, com base em seus escritos mais recentes, pretendo mostrar de que maneira uma teoria crítica da sociedade baseada na "crítica das relações de justificação" está vinculada propriamente a questões da filosofia política normativa (III). E com o intuito de avaliar sua teoria de maneira crítica, por fim, levantarei alguns problemas que dizem respeito ao método "construtivista" assumido pelo autor: apontarei algumas dificuldades em se fundamentar uma crítica da sociedade em uma teoria construtivista que, ao que parece, está fundada no primado "moral" (IV).

1. JAY, M. A imaginação dialética: História da Escola de Frankfurt e do Instituto de Pesquisas Sociais (1923-1950). Rio de Janeiro: Contraponto, 2008, p. 168.

2. Os trabalhos de Neumann estão concentrados, pode-se dizer, nos temas da teoria política e do direito. Cf. NEUMANN, F. O Império do direito. Teoria política e sistema jurídico na sociedade moderna. Tradução de Rúrion Melo. São Paulo: Quartier Latin, 2013.

3. A razão dessa centralidade da política e da democracia no pensamento de Habermas está ancorada em diagnósticos de época bem definidos, sobretudo no contexto da "abertura democrática" depois da segunda guerra mundial. Sobre isso, cf. principalmente SPECTER, M. Habermas: An Intellectual Biograpby. Cambridge Univesity Press, 2010. 
Há um dilema fundamental que acompanha os diversos modelos de teoria crítica em sua história de desenvolvimento. Inicialmente, os processos investigados criticamente são em geral avaliados como manifestações irracionais, injustas e repressivas da condição social existente. Porém, como lembra Axel Honneth, o diagnóstico das patologias sociais (entendido sintomaticamente como "patologias da razão") tem de pressupor um estado social "saudável", não patológico, em que todos os membros da sociedade são capazes de perseguir a autorrealização bem-sucedida de sua vida. ${ }^{4} \mathrm{E}$ isso sem que se apele a "ideais transcendentes" de justiça e de vida boa. Não se trata de uma questão simples. Rainer Forst, um dos mais influentes representantes da teoria crítica atual, pretendeu revisitar esse persistente dilema de modo mais explícito em seu mais recente livro, Crítica das relações de justificação. De acordo com Forst, continuamos tentando saber "porque uma sociedade moderna não está em condição de produzir formas racionais de ordem social. A teoria crítica consiste em uma tentativa de se enfrentar essa questão, mas assim questiona criticamente o próprio conceito de razão utilizado com base em sua 'desrazão' e seu potencial de dominação". ${ }^{5}$

Esse dilema aponta, na verdade, para as pretensões imanentes à "atitude crítica" já esboçada por Max Horkheimer desde o seu texto "Teoria tradicional e teoria crítica", de $1937 .{ }^{6}$ Pois o propósito de fazer uma crítica da sociedade efetivamente existente, ainda que tenha de partir de dentro dos processos sociais analisados, implica um momento reflexivo necessário para colocar em questão justamente a ordem social vigente. Contudo, fica a questão: seria possível adotar uma atitude crítica a um só tempo imanente aos contextos sociais e capaz de apontar para além da ordem funcional estabelecida socialmente? Se o propósito emancipatório da teoria crítica implica uma superação das formas sociais de injustiça, miséria e opressão, de que maneira essa orientação

4. Cf. HONNETH, A. Eine soziale Pathologie der Vernunft. Zur intellektuellen Erbschaft der Kritischen Theorie. In: Pathologien der Vernunft. Geschichte und Gegenwart der Kritischen Theorie. Frankfurt/M: Suhrkamp, 2007.

5. FORST, R. Kritik der Rechtfertigungsverhältnisse: Perspektiven einer kritischen Theorie der Politik. Berlin: Suhrkamp, 2011, p. 18.

6. Cf. HORKHEIMER, M. Traditionelle und kritische Theorie. In: Gesammelte Schriften, Band 4 (1936-1941). Frankfurt/M: Fischer, 2009, pp. 180 e ss. 
prática (entendida no limite na qualidade de práxis política emancipatória) não seria apenas reflexo daquilo que se pretende criticar, já que o próprio ponto de vista da crítica forma parte do contexto da realidade investigada? Desde sempre, portanto, a teoria crítica pressupôs uma espécie de critério crítico cujo ponto de vista normativo precisava ser esclarecido, levando, por seu turno, à procura de um conceito de práxis social adequadamente imanente e reflexivo.

Esse conceito de práxis poderia solucionar dois tipos de déficits centrais identificados no desenvolvimento da teoria crítica. O primeiro deles, apontado principalmente por Habermas, diz respeito ao déficit normativo atribuído à primeira geração da teoria crítica. ${ }^{7}$ Qual ponto de vista normativo nos permite criticar a realidade social? De que maneira podemos adotar uma atitude crítica diante das condições injustas sem que tenhamos o discernimento - que mobiliza nossa crítica - do que poderiam ser as condições justas para uma vida bem sucedida? O segundo, diz respeito a um certo déficit sociológico: de que modo é possível ancorar tais fundamentos normativos da crítica na base da dinâmica social efetiva? ${ }^{8}$

Acontece que critérios crítico-normativos e o ancoramento social de práticas efetivas se entrelaçam de formas diferenciadas e assumem contornos porosos e abertos: uma vez que a teoria crítica já não cristaliza mais algum portador privilegiado da emancipação, é preciso avaliar então a cada vez, diante de novas formas de luta política e de mobilização cultural, se existem expressões efetivas de uma "transcendência na imanência". A centralidade de orientações emancipatórias presas ao paradigma produtivista foi questionada junto com a categoria do "trabalho" (ou da "práxis produtiva"), considerada na tradição marxista capaz de articular ao mesmo tempo elementos normativos e sociológicos. E se estabeleceu um rico diálogo entre a crítica da sociedade e concepções normativas preocupadas com questões de justiça política e social, com a dinâmica política de esferas públicas autônomas, com a participação da sociedade civil e com as lutas por reconhecimento (em que estão envolvidos os dilemas criados por diferenças culturais, orientação sexual, gênero, raça etc.), ou seja,

7. Cf. HABERMAS, J. O discurso filosófico da modernidade. Tradução de Luiz Repa e Ródnei Nascimento. São Paulo: Martins Fontes, 2000, capítulo V.

8. Sobre o "déficit sociológico" na teoria crítica, cf. HONNETH, A. Kritik der Macbt. Frankfurt/M: Suhrkamp, 1989. 
âmbitos de conflitos sociais que requerem uma reflexão renovada sobre a moral, a política e o direito 9 .

Forst voltou-se essencialmente para as questões do pensamento político contemporâneo. Suas preocupações teóricas giram em torno da articulação entre crítica social e filosofia normativa, da reconstrução dos temas clássicos do pensamento político moderno e do enfrentamento dos dilemas contemporâneos ligados às questões de justiça, tolerância, cidadania e direitos humanos ${ }^{10}$. Na verdade, estou menos interessado em especificar os campos e disciplinas tratados por Forst em seu projeto teórico e mais interessado inicialmente em compreender seu empreendimento de um ponto de vista metodológico bastante abrangente, em um caminho de mão-dupla. Em primeiro lugar, quero compreender a maneira pela qual uma teoria crítica da política deveria cumprir a pretensão do ancoramento social da fundamentação normativa. Há uma preocupação crucial em realizar um tipo de crítica da sociedade que seja imanente aos processos histórico e políticos analisados. Contudo, Forst não acredita ser possível uma teoria crítica sem a explicitação de seus pressupostos normativos. "Uma teoria crítica", afirma Forst, "deveria se compreender como 'forma reflexiva de uma razão socialmente efetiva' que apresenta um potencial emancipatório. Ela tem

9. Sobre as diferentes concepções políticas de emancipação em disputa no desenvolvimento da teoria crítica, cf. MELO, R. Marx e Habermas: Teoria crítica e os sentidos da emancipação. São Paulo: Saraiva, 2013.

10. É possível determinar ao menos três momentos complementares na obra de Forst em que a vinculação da filosofia social e da crítica assume a forma de processos autônomos de justificação, os quais são apresentados como formulações parciais de seu projeto mais abrangente de teoria crítica: uma teoria crítica da justiça voltada a "contextos de justificação", que foi elaborada em seu primeiro livro Contextos da justiça. Filosofia política para além de liberalismo e comunitarismo. Tradução de Denilson Luis Werle. São Paulo: Boitempo, 2010; uma teoria crítica da tolerância apoiada tanto em discursos históricos como em uma fundamentação teórico-reflexiva de "justificação da tolerância" (Toleranz im Konflikt. Frankfurt/M: Suhrkamp, 2003; e Os limites da tolerância. Novos Estudos Cebrap, no 84, 2009, pp. 15-29); e uma teoria crítica da política baseada não apenas em uma "crítica das relações de justificação", mas também em uma pesquisa interdisciplinar preocupada com os processos políticos, sociais e institucionais de formação de "ordens normativas" (Das Recbt auf Recbtfertigung. Frankfurt/M: Suhrkamp, 2007; Kritikder Recbtfertigungsverbältnisse; e GÜNTHER, K./FORST, R. (orgs.). Die Herausbildung normativer Ordnungen. Interdisziplinäre perspektiven. Frankfurt/M: Campus, 2011). 
de ser suficientemente sensível tanto para apontar relações sociais injustificadas quanto poder trazer ao conceito reflexivamente (e de modo autorreflexivo) os critérios da crítica". ${ }^{11}$ Portanto, em segundo lugar, parece ser ainda mais imprescindível para a teoria crítica a tarefa de elucidação de seus conceitos normativos fundamentais. Nesse sentido, todos os trabalhos do autor estão perpassados por uma articulação entre teoria social e filosofia normativa, a qual possibilitaria, segundo o autor, uma teoria social e política altamente crítica e reflexiva.

O curioso é que essa articulação teórica (que, na verdade, como ainda veremos, conta com uma junção complexa de elementos fortemente kantianos e certos aspectos hegelianos) é recortada por uma composição disciplinar voltada quase que integralmente para a filosofia política normativa. No entanto, essa composição disciplinar acaba exigindo um esforço de mediação entre suas formulações mais abstratas e uma dimensão propriamente social para a qual o olhar da filosofia não pode mais se desviar. Pois a vinculação entre "filosofia social e crítica"12 explicita um núcleo hegeliano em que as patologias sociais diagnosticadas como uma "desrazão existente" precisam ser confrontadas com a "possibilidade histórica da razão"13. Nessa composição disciplinar em que Forst se orienta, a filosofia política normativa deve ser então altamente "reflexiva": precisa também estar ancorada em processos políticos e sociais, ou seja, na práxis política dos próprios cidadãos.

Postas as pretensões teóricas de nosso autor, apresentarei então os elementos centrais de sua tese sobre os contextos de justificação a partir da discussão dos conflitos normativos nas relações práticas intersubjetivas. Nas duas seções finais, pretendo me concentrar na junção proposta recentemente por Forst entre teoria crítica e filosofia política normativa e no modo como essa junção pode afetar as pretensões do ancoramento social da crítica.

\section{II}

O livro Contextos da justiça, publicado em 1991, consiste em um abrangente estudo sobre a justiça política e social a partir de uma visão

11. FORST, R. Kritik der recbtfertigungsverbältnisse, p. 19.

12. Cf. FORST, R. et. alt. (org.). Sozialpbilosopbie und Kritik. Frankfurt/M: Suhrkamp, 2009.

13. Idem, p. 13 . 
sistemática e crítica do conhecido debate entre liberais e comunitaristas que dominou a cena da teoria política normativa principalmente na década de 1980. Para Forst, a questão central do debate, articulado em torno de questões de justiça, remetia diretamente para o problema da justificação. Liberais e comunitaristas, cada qual a seu modo, lançavam mão de diferentes perspectivas para justificar concepções de justiça aparentemente concorrentes. A crítica comunitarista perpassava quatro campos de discussão cruciais, em que a justificação normativa se explicitava de forma conflituosa: a constituição de um $e$ u, a neutralidade do direito, o ethos da democracia e uma concepção universalista da moral. Cada uma dessas quatro dimensões - ou contextos - admite diferentes modos de justificação de valores e de normas.

Considerados pontos de vista opostos de justificação, liberais e comunitaristas acabaram separando contextos práticos intersubjetivos que, apesar de poderem ser de certo modo diferenciados, não poderiam pretender determinar unilateralmente a dimensão correta e única em que se baseia a justificação. Pois se reforçássemos, como pretendem os liberais, a neutralidade do direito, uma concepção "transcendental" de pessoa racional e uma moral universalista, sublinhando assim a prioridade do justo diante do bem, então a justificação normativa estaria fundada de modo totalmente indiferente ao contexto. Contrariamente, se atribuíssemos um peso central à dimensão da pessoa ética, à ligação entre direitos e valores, democracia e bem comum, reforçaríamos, com os comunitaristas, uma posição obcecada pelo contexto. ${ }^{14}$

Forst, indo além dessa oposição, acredita ser necessário formular uma teoria crítica da justiça capaz de justificar o ancoramento dos princípios normativos nos valores, nas práticas e nas instituições da comunidade política, compatibilizando dessa maneira os aspectos universalistas com a reivindicação de validade daqueles princípios para a autocompreensão e instituições sociais específicas ${ }^{15}$. Forst pretende mostrar a possibilidade de "superar" tais oposições tradicionais segundo uma "perspectiva vertical" a partir de sua tese dos "contextos da justiça". Uma teoria crítica da justiça precisa antes considerar as necessidades que podem surgir no contexto de socialização dos indiví-

14. Cf. FORST, R. Contextos da justiça, p. 11.

15. Sobre a teoria crítica da justiça, cf. também MELO, R. Autonomia, justiça e democracia. Novos Estudos CEBRAP, n. 88, 2010. 
duos e devem ser justificadas publicamente em dimensões ao mesmo tempo diferenciadas e interrelacionadas. Argumentos universalistas, pretensões de neutralidade jurídica e dimensões axiológicas compõem os contextos de reconhecimento e de justificação pública nos âmbitos da moral, do direito, da ética e da política. "Eles formam", comenta Forst, "quatro 'contextos' de reconhecimento recíproco - como pessoa ética, pessoa do direito, cidadão(ã) com plenos direitos, pessoa moral - que correspondem a diferentes modos de justificação normativa de valores e de normas em diferentes 'comunidades de justificação"'. ${ }^{\prime 6}$

Portanto, a práxis de justificação parece nela mesma pressupor uma universalidade (e imparcialidade) que, elucidada em relação aos seus contextos normativos, corresponde também aos interesses, necessidades e valores concretos dos concernidos. ${ }^{17} \mathrm{O}$ propósito crítico da diferenciação e da articulação dos diversos contextos consiste menos na separação entre o plano ético, jurídico, político e moral, do que na possibilidade de "comprovar a compatibilidade dos direitos individuais com o bem da comunidade, da universalidade política com a diferença ética, do universalismo moral com o contextualismo", permitindo desse modo "evitar oposições falsas". ${ }^{18}$

Ao considerar então que, do ponto de vista normativo, as pessoas sempre se encontram "situadas" em determinados contextos (ético, jurídico, político e moral), Forst pretende dar atenção a uma práxis de justificação diferenciada. Quando se defrontam com possíveis conflitos normativos, as pessoas lidam com questões práticas que precisam ser respondidas com boas razões e em que são exigidas justificações determinadas. Em outros termos, ainda que os conflitos normativos sempre devam ser resolvidos por pessoas situadas no interior de contextos intersubjetivos, é preciso antes de tudo diferenciá-los e entender que as questões práticas surgidas sempre exigem respostas justificadas de forma diferente. Forst enfatiza com isso não uma mera diferenciação (ou formalização) dos ideais de vida boa, mas antes a própria práxis de justificação que emerge dos conflitos normativos, vale dizer, uma diferenciação dos contextos práticos constituídos pela exigência

16. FORST, R. Contextos da justiça, p. 275.

17. Idem, p. 276.

18. Idem, p. 13. 
de que normas e valores precisam ser justificados de modo intersubjetivo.

Um dos principais conceitos utilizados por Forst nas quatro dimensões como mediação para redefinir os conceitos de pessoa de direito, cidadania ou de uma moral universalista em contextos intersubjetivos diferenciados é o de autonomia. "Segundo esse conceito", afirma Forst,

as pessoas como agentes são, no sentido prático, seres "autônomos" autodeterminantes quando agem de forma consciente e fundamentada. Como tais são responsáveis por suas ações: podem ser questionadas acerca das razões pelas quais agiram. Como pessoas responsáveis, são aquelas "que se justificam" e esperamos que tenham considerado suas razões para agir, sendo capazes de justificá-las. Nesse sentido, as pessoas autônomas são razoáveis em termos de razão prática: possuem razões para agir que podem ser justificadas para elas mesmas e comunicadas e defendidas diante de outras, de modo que essas razões [...] possam ser compartilhadas. ${ }^{19}$

Também uma diferenciação nos "contextos da autonomia" poderá nos mostrar quais questões práticas e quais respostas autônomas podem se apoiar em razões capazes de ser publicamente reconhecidas. Esses contextos da autonomia estão vinculados aos diferentes contextos de justificação já especificados. E tanto agora como antes, trata-se de evitar a supervalorização de uma determinada concepção de autonomia sobre outras, procurando, pelo contrário, compatibilizar as diferentes autonomias, evitar falsas oposições e compreender os conflitos que surgem da relação entre as justificações práticas e o próprio conceito de autonomia. A autonomia ética das pessoas está vinculada à vida boa e à validade de valores éticos; a autonomia jurídica diz respeito aos destinatários do direito; a autonomia política se funda na concepção do cidadão como autor do direito; e a autonomia moral concerne às pessoas na qualidade de autoras e destinatárias de normas morais. Liberais e comunitaristas não compreenderam justamente que nenhuma dessas concepções de autonomia pode pretender ser a única válida como base da justiça. Por essa razão, a tarefa da análise crítica é saber como integrá-las, compatibilizá-las e perceber

19. Idem, p. 305. 
quando entram em conflito "de modo que uma dimensão não seja sacrificada em nome das outras". ${ }^{20}$

Por fim, a essa distinção analítica entre diferentes contextos de justificação, que precisa ser fundamentada em um conceito intersubjetivo de razão prática, corresponde também um processo de reconbecimento multidimensional. Pois se a razão prática explicita que normas e valores devem ser justificados no respectivo contexto em que reivindicam validade, "são pessoas concretas que apresentam pretensões de validade e as fundamentam em diferentes 'comunidades de justificação"'. ${ }^{21}$ Essa complementação da teoria do reconhecimento é necessária, segundo Forst, porque os contextos de justificação são constituídos por pessoas que agem autonomamente, ou seja, precisam se justificar em contextos intersubjetivos diferenciados.

A partir da explicação teórica moral da questão da justificação como vista a partir da perspectiva performática de pessoas que têm de resgatar pretensões de validade diante e dentro das comunidades segue-se que, nesses níveis, as pessoas são reconbecidas como membros de comunidades (diferentes), reconhecem a si mesmos e aos outros. Por conseguinte, a análise de diferentes comunidades de justificação - que se funda num conceito de razão prática justificadora - a ponta para diferentes relações de reconhecimento. ${ }^{22}$

O conceito de reconhecimento também possui uma vantagem normativa adicional para a superação da oposição entre liberais e comunitaristas. Pois assumindo que a práxis de justificação só pode ocorrer por intermédio de pessoas contextualmente situadas, aponta-se para além da dicotomia indivíduo versus sociedade, a qual perpassou todas as oposições criticadas no debate analisado. O reconhecimento permite equilibrar aspectos universalistas com uma formação não opressiva da individualidade, isto é, "reconciliar identidade e diferença sem absolutizar um dos lados" ${ }^{23}$ Ser reconhecido por outros e reconhecê-los respectivamente significa reconhecimento recíproco na qualidade de indivíduos ou de seres situados em comunidades. Para Forst, é preciso dar atenção ao desenvolvimento dinâmico daquilo que

20. Idem, p. 306.

21. Idem, p. 286.

22. Idem, p. 326.

23. Idem, p. 328. 
Habermas entendeu como uma "individuação pela socialização"24, capaz ao mesmo tempo de enraizar os conceitos da teoria da justiça na vida social e subjetiva e, ao lado da ideia dos contextos de justificação, distinguir intersubjetivamente formas diferentes de individualidade e vínculos comunitários.

\section{III}

Contextos da justiça oferece sem dúvida uma solução normativamente elegante no quadro de debates levados a cabo pelas teorias da justiça. Ademais, já nesse primeiro momento da obra de Forst parece clara a pretensão crítica de sua contribuição: de um lado, fundamentações normativas e práxis política precisam estar articuladas de modo bem específico na formulação de uma "crítica das relações de justificação"; de outro, em paralelo à elucidação dos diferentes graus em que ocorre tal articulação, há o pressuposto de que teorias de justiça são potencialmente críticas quando questões práticas controversas mobilizam processos de justificação normativa. Pois a própria práxis de justificação, que recorre a critérios normativos fortes, nasce ancorada em conflitos históricos e dinâmicas políticas bem determinadas. Por essa razão, o vínculo entre teoria crítica e filosofia política normativa é apresentado em seu mais recente livro de forma tão articulada:

Eu parto assim da questão central da justificação da dominação política e a transformo reflexivamente: quem, na verdade, levanta essa questão, e quem tem autoridade para respondê-la? É tempo de relembrar do tema político central da filosofia política e conceber a questão filosófica de fundamentação como uma questão prática, isto é, radicalizar e ao mesmo tempo contextualizar a ideia de justificação. ${ }^{25}$

Essa transformação reflexiva da questão central da justificação da dominação política permite superar a dicotomia estabelecida entre ideia e realidade (entre razão e história, moral e política). Na verdade, a questão da justificação é suficientemente concreta, uma vez que nasce dos conflitos sociais e políticos ocorridos na história. Além disso, toda exigência de justificação é reflexiva de maneira prática, ou seja,

24. HABERMAS, J. Individuierung duch Vergesellschaftung. In: Nacbmetapbysisches Denken. Frankfurt/M: Suhrkamp, 1991.

25. FORST, R. Kritik der Rechfertigungsverbältnisse, p. 13. 
é constituída por uma práxis de justificação efetiva, por uma práxis concebida na qualidade de princípio da razão prática no mundo político. Esse princípio é tanto histórico quanto, se se quiser, "apriorístico", já que apela ao princípio de justificação que diz que, segundo sua pretensão de validade, as normas sempre têm de ser fundamentadas. Por essa razão, na filosofia política, trata-se de desenvolver de modo consequente a perspectiva dos participantes nas práticas de justificação. O principal consiste no seguinte pressuposto crítico-normativ: se considerarmos as pessoas como seres sociais e igualmente autônomos, que podem (e devem poder) determinar ativamente as estruturas normativas válidas para elas, então estamos diante de um padrão ao mesmo tempo imanente e transcendente à práxis: ninguém está totalmente inserido em uma práxis de justificação, pois sempre há a possibilidade de questionar e criticar reflexivamente essa práxis. Apenas uma crítica das relações de justificação pode analisar se essa possibilidade é real.

Ao tratar a exigência de justificação como um princípio da razão prática, Forst pretende mostrar não apenas as contrições normativas que determinam esse princípio - fundamentado em condições exigentes de aceitabilidade racional - , mas também insistir que se trata de um tipo de imperativo prático que se impõe historicamente em condições de conflito. Pois ser racional não significa somente saber quando algo tem de ser justificado, mas também que isso é exigido quando se trata da dominação sobre outros. Estes outros possuem cada qual um irredutível direito à justificação caso se trate de saber quem devem seguir e o que devem aceitar - e eles também têm um dever de se justificar caso se trate de suas próprias pretensões. ${ }^{26}$ Pressupõe-se assim um tipo de procedimento hipotético e, podemos dizer, contrafactual de argumentação moral inerente às práticas justificadoras, na medida em que estas são exigências morais que recortam os discursos políticos e a moralidade cotidiana e norteiam um horizonte de pressupostos normativos, suposições e relações de poder.

Ainda que se trate de especificar a questão política fundamental que conduz ao problema da justificação, há uma necessidade de mostrar que problemas de poder, injustiça e dominação não se limitam à esfera do político. Forst tem em vista uma análise crítica da sociedade

26. Cf. FORST, R. Soziale Gerechtigkeit, Rechtfertigung und Macht. In: . Das Recht auf Rechtfertigung, pp. 270 e ss. 
preocupada não apenas com relações sociais e políticas justificadoras, mas também econômicas e culturais ${ }^{27}$. Incluem-se aqui todas aquelas relações e estruturas sociais mais ou menos institucionalizadas que não fazem justiça ao critério de justificação recíproca e universal e são caracterizadas pelas formas de exclusão, de privilégios e de controle. ${ }^{28}$

Além disso, uma teoria crítica da política implica uma crítica teórico-discursiva que em parte também é uma crítica genealógica de justificações "falsas" (possivelmente ideológicas) de relações sociais assimétricas, ou seja, daquelas legitimações que não apresentam relações e estruturas justificadoras como sendo fundamentadas. Nesse caso, os critérios morais de reciprocidade e universalidade servem como ponto de referência essencial, ainda que normalmente não conduzam a respostas definitivas, pois estas teriam antes de ser obtidas entre os concernidos. Essa teoria não exige apenas que as relações sociais e políticas sejam justificadas, mas, reflexivamente falando, exige que uma "estrutura básica de justificação" seja o primeiro imperativo da justiça. Não certamente na qualidade de roteiro completo que seria apenas "aplicado", mas de espaços para uma práxis discursiva autônoma dos próprios concernidos - incluindo a questão sobre o que significa "ser um concernido" ou "estar submetido", pois o direito à justificação não termina nas fronteiras dos contextos de justificação estatais. ${ }^{29}$ Uma

27. Em seu artigo sobre liberdade política, Forst acrescentou aos quatro contextos de autonomia (ético, moral, jurídico e político) uma dimensão socioeconômica. Cf. FORST, R. Politische Freiheit. In: Das Recht auf Recbtfertigung, pp. 189-210. Sobre essa questão, ver ainda sua contribuição ao debate acerca do tema redistribuição/reconhecimento em FORST, R. Das Wichtigste zuerst. Umverteilung, Anerkennung und Rechtfertigung. In: Krtitik der Rechtfertigungsverbältnisse, pp. 134-154.

28. Sobre as relações de justificação e sua vinculação com a construção de diferentes ordens normativas, cf. GÜNTHER, K./FORST, R. Die Herausbildung normativer Ordnungen. Zur Idee eines interdiziplinären Forschungsprogramms. In: (orgs.). Die Herausbildung normativer Ordnungen, pp. 11 e ss.

29. Sobre isso, cf. FORST, Das Recht auf Rechtfertigung, Parte III. A ideia básica consiste em assumir radicalmente que princípios objetivos de justiça - bem como sua aplicação em termos redistributivos - devem estar ancorados nas práticas de justificação de tais princípios. Não há "justiça" sem que os critérios normativos do justo/injusto sejam justificados intersubjetivamente pelos concernidos. Com isso, Forst acredita submeter a discussão sobre a justiça a critérios morais de universalidade e reciprocidade (ambos sempre atrelados 
crítica abrangente das relações de justificação exige, por fim, um esclarecimento dos fracassos ou falhas das estruturas sociais e políticas eficazes de justificação capaz de desmascarar e transformar as relações injustas. Para tanto, são essenciais as perspectivas históricas e sociais a serem analisadas.

Sendo assim, uma teoria crítica da política tem de poder organizar os critérios que orientam sua própria atividade crítica com determinados limites de seu próprio contexto de aplicação: "Ela não pode fabricar quaisquer normas ou ideais 'absolutos', mas sim remeter consequentemente aquela pretensão de validade à possibilidade de consentimento por parte daqueles que estão sujeitos à norma. Esse princípio vale como princípio indispensável para a crítica" ${ }^{30} \mathrm{O}$ esclarecimento desses limites - em que se identificam injustiças, desigualdades e imposições legitimadoras em determinadas ordens normativas - remete novamente a processos políticos reflexivos radicais em termos de autodeterminação: as ordens normativas são recursivamente avaliadas a partir das práticas justificadoras que as tornam mais ou menos aceitáveis. Desse modo, a perspectiva da justificação da dominação política permite posicionar o ponto de vista normativo no interior das práticas distorcidas ou falseadas, consideradas insuficientes para o padrão de uma razão prática justificadora. De qualquer modo, sublinha-se aqui não apenas a questão da dominação política enquanto tal, mas a perspectiva normativa radical para a avaliação da gênese das relações de dominação social e política. Porém, fica a questão: podemos mesmo considerar como "crítica" uma teoria política reflexiva unicamente por ela se apoiar de maneira recursiva em um tipo de construção de ordens normativas que, por razões morais, devem ser reciprocamente justificáveis e universalmente legítimas?

\section{IV}

O recurso à justificação enquanto uma prática social efetiva (que está vinculada simultaneamente a contextos históricos e a pretensões reflexivas de crítica normativa), permite, segundo Forst, evitar uma série de oposições que dizem respeito à possibilidade de princípios

a práticas justificadoras) considerados, segundo ele, imprescindíveis para a teoria crítica.

30. FORST, R. Kritik der Rechtfertigungsverbältnisse, p. 21. 
universalistas, à força imanente da razão, à historicidade de normas e à relação entre moral e política. Por ser a justificação uma prática que sempre veio ao mundo em momentos de conflito na história política dos homens, a estrutura racional e universalista que estaria pressuposta em toda forma comunicativa, em todo contexto intersubjetivo de organização política e social, não corresponderia a uma mera ideia utópica que paira acima das práticas concretas. Para utilizarmos uma expressão de Habermas, as relações de justificação se realizam sempre em um processo de tensão entre facticidade e validade. Habermas desenvolveu pelo viés da comunicação uma crítica social pretensamente imanente que adotava a forma de uma "transcendência a partir de dentro $^{\prime 31}$. Forst, acompanhando o propósito reconstrutivo de Habermas, também entende que a teoria crítica precisa "desenvolver de modo consequente a perspectiva dos participantes nas práticas de justificação, o que mostra mais uma vez o aspecto supérfluo de uma outra oposição, muito discutida, entre uma perspectiva 'imanente' e outra 'transcendente"'. ${ }^{32}$

Do ponto de vista da fundamentação, Forst não recorre a algo como uma teoria da razão prática. Na verdade, a razão, segundo Forst, é naturalmente prática, pois depende de uma práxis que torna possível que algo (valores, opiniões, normas etc.) possa ser fundamentado e aceito como racionalmente válido. ${ }^{33}$ Ora, se não estamos lidando com a explicitação de condições transcendentais da razão prática e nem atribuindo um papel tão fundamental ao contexto a ponto de afirmar que valeria como uma razão justificadora aquilo que emerge imediatamente de práticas históricas, como articular ambos os planos (o da imanência e o da transcendência) de modo adequado? Forst parece partir da constatação do fato da justificação, o qual não decorreria da pré-existência de uma razão prática como uma espécie de capacidade

31. Cf. HABERMAS, J. Faktizität und Geltung. Frankfurt/M: Suhrkamp, 1994, pp. 32 e ss. Sobre essa questão no âmbito da teoria crítica do direito e da democracia em Habermas, cf. MELO, R./SILVA, F. G. Crítica e reconstrução em Direito e democracia. In: NOBRE, M./REPA, L. (org.). Habermas e a reconstrução: Sobre a categoria central da teoria crítica babermasiana. Campinas: Papirus, 2012.

32. FORST, R. Kritik der Rechtfertigungsverbältnisse, p. 16.

33. Cf. FORST, R. Praktische Vernunft und rechtfertigende Gründe. Zür Begründung der Moral. In: Das Recht auf Rechtfertingung, pp. 23 e ss. 
transcendental das pessoas. Na verdade, Forst adota o caminho inverso. A própria razão prática (considerada como uma razão prática justificadora) se manifesta em decorrência da exigência de justificação intersubjetiva em contextos normativos.

Cabe notar, contudo, que tratar a justificação como um fato indispensável da realidade política e social talvez não seja suficiente para ancorar a transcendência efetivamente "a partir de dentro". E, neste ponto, eu gostaria de apontar muito brevemente o que entendo ser, até o momento do desenvolvimento de sua teoria crítica da política, um possível "ponto fraco" de Forst - uma vez assumindo as exigências de fundamentação e de crítica imanente próprias da teoria crítica. Pode a efetividade de uma teoria da sociedade pode estar ancorada apenas na pressuposição de que as relações de justificação são uma práxis discursiva? Não evitaria esse procedimento de fundamentação justamente a necessidade de recorrer a uma teoria social? Acredito que sim, e que esse "déficit sociológico" da teoria de Forst parece se tornar mais explícito quando se assume que a crítica das relações de justificação depende de uma fundamentação meramente construtivista.

Para entendermos o que seria o método construtivo de Forst, é preciso levar a sério que o fato da justificação precisa assumir o ponto de partida da construção teórica. Uma vez que questões de justificação surgem inevitavelmente em contextos sociais e políticos - pela própria existência, como vimos, da dominação histórica -, toda tentativa de fundamentação das relações de justificação remete inevitavelmente à própria prática discursiva que tornam aquelas justificações possíveis. Ou seja, nessas relações existem "exigências recursivas" ${ }^{\text {"34 }}$ que fazem com que, para entendê-las, tenhamos de recorrer aos próprios elementos que as caracterizam. Desse modo, porque o princípio de justificação é ao mesmo tempo um princípio de autonomia e de crítica, "a teoria assume esse princípio como seu fundamento, ou seja, ela não constrói uma ordem normativa por cima de sua cabeça, mas tenta pensar essa mesma ordem como seu produto construtivo" ${ }^{\prime \prime 3}$.

Há, portanto, um sentido de construção que diz respeito ao próprio método analítico de Forst. Dada a existência da práxis de justificação, temos de pressupor pessoas autônomas capazes de demandar

34. FORST, R. Kritik der Rechtfertigungsverbältnisse, p. 15.

35. Idem, p. 18. 
e oferecer razões por meio de uma prática comunicativa em contextos intersubjetivos normativamente diferenciados. Em outros termos, sem pressupormos autonomia, pessoas deliberativas, contextos intersubjetivos e relações de reconhecimento, não existiriam relações de justificação. Mas, além desse aspecto obtido analiticamente, há ainda um sentido normativo de construção: a práxis de justificação faz com que concernidos e participantes sejam autores das ordens normativas às quais estão submetidos.

Ambos os sentidos, o analítico e o normativo, podem ser "recursivamente" construídos porque especificam justamente aquelas pretensões morais de validade de normas que devem ser justificáveis e legitimadas reciprocamente: as pretensões de tais normas devem ser testadas discursivamente por uma práxis de justificação responsável por produzir universal e reciprocamente razões ao menos não-rejeitáveis. Por isso, a justificação precisa pressupor analítica e normativamente um ponto de vista moral, sem o qual a própria práxis justificadora não seria teoricamente sustentada. Além disso, ancora sua construção normativa em um tipo de práxis que, para acontecer, manifesta a pretensão moral desempenhada em toda relação de justificação. Sendo assim, a justificação valida moralmente toda a construção de ordens normativas que, ao serem avaliadas quanto à sua legitimidade, remetem de maneira recursiva novamente a práticas exitosas de justificação normativa.

Ora, se existem elementos pressupostos na teoria de Forst que foram historicamente "reconstruídos", ainda não fica claro qual é sua relação com o núcleo normativo da práxis de justificação. ${ }^{36}$ Como evitar realmente que o "fato da justificação" não seja apenas uma construção ideal derivada das exigências estabelecidas por uma práxis discursiva moralmente construída? Pois a práxis de justificação não está fundada, antes de tudo, nos pressupostos morais da universalidade e da reciprocidade, independentemente de sua gênese histórica e política concreta? Parece evidente que Forst pretende evitar recaídas relativistas para ancorar seu próprio conceito de

36. Forst geralmente remete à história quando pretende ancorar seus conceitos em processos efetivos. Com isso, pretende articular tais conceitos em contextos efetivos. Cf. FORST, R. Toleranz im Konflikt, p. 31 e ss. Porém, a história parece ocupar apenas um papel de "exemplo" (não de gênese) para as determinações normativas analiticamente construídas. 
crítica. Mas podemos fundá-lo somente sobre uma construção moral? Desde a primeira geração, a teoria crítica pretendeu não "construir" simplesmente categorias e conceitos, mas explicitar a gênese destes em determinados diagnóstico de época. "Contextos de surgimento" e "contextos de aplicação" da teoria não podem ser construídos abstratamente, nem mesmo se pressupomos que foram produzidos a partir da perspectiva dos concernidos $^{37}$. Mas neste ponto Forst parece seguir mais Rawls do que Habermas, ao optar por uma teoria construtivista e não reconstrutiva ${ }^{38}$. Para Habermas, as potencialidades emancipatórias estão ligadas ao conceito de ação comunicativa. Mas isso implica (além do ponto de partida do diagnóstico social) uma reconstrução teórica capaz de desvendar, na reprodução da sociedade, os elementos de uma racionalidade existente (vinculando uma teoria da modernidade preocupada com processos de racionalização bem como uma teoria da ação social) ${ }^{39}$. Não se trata aqui de expor o que estaria em jogo no procedimento reconstrutivo, pois isso exigiria uma outra investigação abrangente e complexa. Trata-se tão somente de exigir de uma teoria crítica da política a explicitação de seu contexto de surgimento.

37. Cf. HABERMAS, J. Teoria e práxis. Estudos de filosofia social. Tradução de Rúrion Melo. São Paulo: Unesp, 2013, Introdução.

38. Existem, é verdade, acentuadas diferenças e aspectos semelhantes entre o construtivismo rawlsiano e a reconstrução habermasiana. Cf. WERLE, D. L. Construtivismo 'não metafísico' e reconstrução 'pós-metafísica': o debate Rawls-Habermas. In: NOBRE, M./REPA, L. (orgs.). Habermas e a reconstrução, pp. 169-196.

39. Também Axel Honneth procurou adotar a via de uma "reconstrução normativa" preocupada com a gênese das categorias críticas. Dirigindo-se contra uma crítica de Forst à teoria do reconhecimento, Honneth afirmou: "Não podemos aceitar essas condições de justificação como meramente dadas e imunes à análise, mas antes temos de reconstruí-las em termos de sua gênese e estruturas normativas, porque são estas que determinam os elementos da justiça". HONNETH, A. Rejoinder. In: PETHERBRIDGE, D. (org). Axel Honneth: Critical Essays. Boston: Brill, 2011, p. 416. Elaborei uma crítica da postura honnethiana (por reduzir demais a justificação política à perspectiva da autorrealização ética) em MELO, R./WERLE, D. L. Um déficit político do liberalismo hegeliano? Autonomia e reconhecimento em Honneth. In: MELO, R. (org.). A teoria crítica de Axel Honneth. Reconbecimento, liberdade e justiça. São Paulo: Saraiva, 2013, pp. 317-335. 


\section{Referências bibliográficas:}

FORST, R. Toleranz im Konflikt. Frankfurt/M: Suhrkamp, 2003. . Das Recbt auf Rechtfertigung. Frankfurt/M: Suhrkamp, 2007. Soziale Gerechtigkeit, Rechtfertigung und Macht. In: Das Recht auf Rechtfertigung. Frankfurt/M: Suhrkamp, 2007. Praktische Vernunft und rechtfertigende Gründe. Zür Begründung der Moral. In: FORST, R. Das Recht auf Rechtfertingung. Frankfurt/M: Suhrkamp, 2007.

Politische Freiheit. In: Das Recbt auf Recbtfertigung.

Frankfurt/M: Suhrkamp, 2007.

Os limites da tolerância. Novos Estudos Cebrap, n. 84, 2009.

Contextos da justiça. Filosofia política para além de liberalismo e comunitarismo. Tradução de Denilson Luis Werle. São Paulo: Boitempo, 2010.

Kritik der Rechtfertigungsverbältnisse: Perspektiven einer kritischen Theorie der Politik. Berlin: Suhrkamp, 2011.

Das Wichtigste zuerst. Umverteilung, Anerkennung und Rechtfertigung. In: Krtitik der Rechtfertigungsverbältnisse. Berlin: Suhrkamp, 2011.

FORST, R. et. alt. (org.). Sozialpbilosopbie und Kritik. Frankfurt/M: Suhrkamp, 2009.

GÜNTHER, K./FORST, R. (orgs.). Die Herausbildung normativer Ordnungen. Interdisziplinäre perspektiven. Frankfurt/M: Campus, 2011.

Die Herausbildung normativer Ordnungen. Zur Idee eines interdiziplinären Forschungsprogramms. In: GÜNTHER, K./ FORST, R. (orgs.). Die Herausbildung normativer Ordnungen. Frankfurt/M: Campus, 2011.

HABERMAS, J. Individuierung duch Vergesellschaftung. In:

Nachmetapbysisches Denken. Frankfurt/M: Suhrkamp, 1991. Faktizität und Geltung. Frankfurt/M: Suhrkamp, 1994.

O discurso filosófico da modernidade. Tradução de Luiz Repa e Ródnei Nascimento. São Paulo: Martins Fontes, 2000.

HABERMAS, J. Teoria e práxis. Estudos de filosofia social. Tradução de Rúrion Melo. São Paulo: Unesp, 2013.

HONNETH, A. Kritik der Macbt. Frankfurt/M: Suhrkamp, 1989.

Eine soziale Pathologie der Vernunft. Zur intellektuellen Erbschaft der Kritischen Theorie. In: Pathologien der Vernunft. Geschicbte und Gegenwart der Kritischen Theorie. Frankfurt/M: Suhrkamp, 2007. 
Rejoinder. In: PETHERBRIDGE, D. (org). Axel Honneth: Critical Essays. Boston: Brill, 2011.

HORKHEIMER, M. Traditionelle und kritische Theorie. In: Gesammelte Schriften, Band 4 (1936-1941). Frankfurt/M: Fischer, 2009.

JAY, M. A imaginação dialética: História da Escola de Frankfurt e do Instituto de Pesquisas Sociais (1923-1950). Rio de Janeiro: Contraponto, 2008.

MELO, R. Autonomia, justiça e democracia. Novos Estudos CEBRAP, n. $88,2010$.

Marx e Habermas: Teoria crítica e os sentidos da emancipação. São Paulo: Saraiva, 2013.

MELO, R./SILVA, F. G. Crítica e reconstrução em Direito e democracia. In: NOBRE, M./REPA, L. (org.). Habermas e a reconstrução: Sobre a categoria central da teoria crítica babermasiana. Campinas: Papirus, 2012.

MELO, R./WERLE, D. L. Um déficit político do liberalismo hegeliano? Autonomia e reconhecimento em Honneth. In: MELO, R. (org.). A teoria crítica de Axel Honneth. Reconbecimento, liberdade e justiça. São Paulo: Saraiva, 2013.

NEUMANN, F. O Império do direito. Teoria política e sistema jurídico na sociedade moderna. Tradução de Rúrion Melo. São Paulo: Quartier Latin, 2013.

SPECTER, M. Habermas: An Intellectual Biograpby. Cambridge Univesity Press, 2010.

WERLE, D. L. Construtivismo 'não metafísico' e reconstrução 'pós-metafísica': o debate Rawls-Habermas. In: NOBRE, M./REPA, L. (orgs.). Habermas e a reconstrução. Campinas: Papirus, 2012. 